\title{
A Japanese family with nonautoimmune hyperthyroidism caused by a novel heterozygous thyrotropin receptor gene mutation
}

\author{
Akie Nakamura', Shuntaro Morikawa' ${ }^{1}$, Hayato Aoyagi ${ }^{2}$, Katsura Ishizu' and Toshihiro Tajima'
}

BACKGROUND: Hyperthyroidism caused by activating mutations of the thyrotropin receptor gene (TSHR) is rare in the pediatric population.

METHODS: We found a Japanese family with hyperthyroidism without autoantibody. DNA sequence analysis of TSHR was undertaken in this family. The functional consequences for the Gs-adenylyl cyclase and Gq/11-phospholipase C signaling pathways and cell surface expression of receptors were determined in vitro using transiently transfected human embryonic kidney 293 cells.

RESULTS: We identified a heterozygous mutation (M453R) in exon 10 of TSHR. In this family, this mutation was found in all individuals who exhibited hyperthyroidism. The results showed that this mutation resulted in constitutive activation of the Gs-adenylyl cyclase system. However, this mutation also caused a reduction in the activation capacity of the Gq/11phospholipase C pathway, compared with the wild type.

CONCLUSION: We demonstrate that the M453R mutation is the cause of nonautoimmune hyperthyroidism.

$\mathbf{T}$ hyrotropin (TSH) receptor (TSHR) is a plasma membrane $\mathrm{G}$ protein-coupled receptor (GPCR), a member of a large superfamily of GPCRs (1). This receptor consists of seven transmembrane domains (TMDs) and a large extracellular domain (ECD) that mediates the effect of TSH in thyroid development, growth, and hormone synthesis $(1,2)$. TSH binds the TSHR and activates two signal transduction pathways: the Gs/adenylyl cyclase and Gq-phospholipase C pathways $(2,3)$. The Gs/adenylyl cyclase system is thought to be important for most TSH-induced effects on the growth and the function of the thyroid gland $(1,2)$. Moreover, it has been reported that the Gq/11-phospholipase C pathway is involved in thyroid hormone synthesis and growth of the thyroid gland (3).

Activating germline mutations of TSHR cause nonautoimmune sporadic congenital hyperthyroidism or familial nonautoimmune hyperthyroidism (4-13). To date, gain-of-function mutations in TMD 1, 2, 3, 5, 6, and 7 and in the ECD have been reported (4-13). These mutations have been shown to activate the Gs/adenylyl cyclase system in a ligand-independent manner (4-13).

In this study, we report a Japanese family with nonautoimmune hyperthyroidism caused by a gain-of-function mutation (M435R) in TMD2. An in vitro study demonstrated that M453R causes constitutive activation of the Gs/adenylyl cyclase pathway in the absence of a ligand, but it also results in loss of the activating function of the Gq/11-phospholipase C pathway.

\section{CASE REPORTS}

The pedigree of the proband and her family is shown in Figure 1a. The proband is denoted by the arrow. Family members with hyperthyroid who were subjected to gene analysis are shown by half solid squares and circles.

\section{Case 1}

The proband (a younger sister) was delivered at 38-wk gestation by normal vaginal delivery as the second child of unrelated Japanese parents. Her birth weight was $2,482 \mathrm{~g}$, length was $45.8 \mathrm{~cm}$, and head circumference was $35 \mathrm{~cm}$. Because her mother had been diagnosed as having nonautoimmune hyperthyroidism 2 y before pregnancy of case 1, we tested thyroid function in cord blood at birth. The results were as follows: levels of FT3, FT4, and TSH in cord blood were $1.23 \mathrm{pg} / \mathrm{ml}, 0.75 \mathrm{ng} /$ $\mathrm{dl}$, and $8.789 \mu \mathrm{U} / \mathrm{ml}$, respectively. At the age of $1 \mathrm{mo}$, she was observed to have tachycardia with a heart rate of 150 beats/min and poor body weight gain (body weight was $3,282 \mathrm{~g}$ ). She did not have a goiter or exophthalmos. Laboratory tests confirmed hyperthyroidism with a TSH level of $<0.03 \mu \mathrm{U} / \mathrm{ml}$ (normal range: $0.4-4$ ), FT4 level of $3.12 \mathrm{ng} / \mathrm{dl}$ (normal range for age: $0.8-1.9$ ), and FT3 level of $8.36 \mathrm{pg} / \mathrm{ml}$ (normal range for age: 1.6-4.7). No TRAb or thyroid stimulating antibody (TSAb) was identified in the patient. Based on these findings, she was also diagnosed as having nonautoimmune hyperthyroidism, and treatment with thiamazole $(2 \mathrm{mg} / \mathrm{d})$ was initiated. After $3 \mathrm{wk}$ of thiamazole treatment, a euthyroid state was achieved. Thyroid hormone levels continued to fluctuate within the normal range; however, reduction of thiamazole resulted in the elevation of 
a

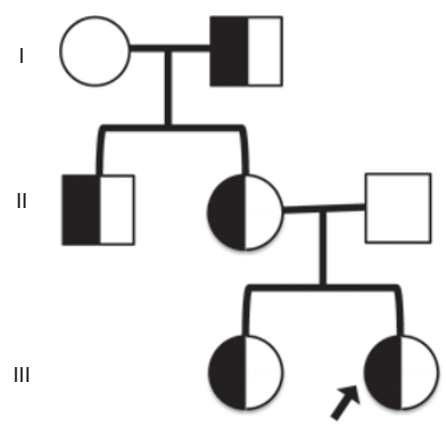

b Antisense

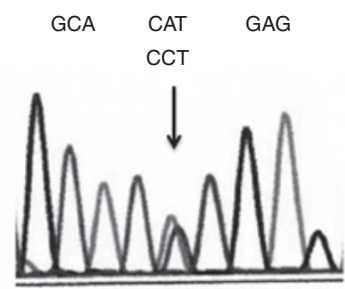

C

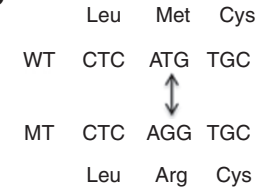

Figure 1. Analysis of TSHR in the family. (a) Pedigree of the family. The arrow indicates the proband. Squares and circles indicate males and females, respectively. Half solid squares and circles indicate the members who were diagnosed as having hyperthyroidism and subjected to gene analysis. (b) Sequencing of exon 10 of thyrotropin receptor (TSHR) identified both $\mathrm{C}$ and $\mathrm{A}$ nucleotides, denoted by the arrow. Note that this sequence is an antisense strand. (c) This base change results in substitution of arginine for methionine as a heterozygous state.

thyroid hormone and suppression of TSH levels. Goiter was noticed at the age of $2.5 \mathrm{y}$ at regular evaluation. At the age of $5 \mathrm{y}$, thyroid ultrasonography showed diffuse enlargement of the thyroid gland, with a total volume of $9.7 \mathrm{~cm}^{3}$ (normal: $3.3 \pm 1.0 \mathrm{~cm}^{3}$ for her age) (14) and high blood flow in the thyroid tissue. Now aged $6 \mathrm{y}$, she continues to receive thiamazole at $10 \mathrm{mg} / \mathrm{d}$. Her height is $111.3 \mathrm{~cm}(-1.2 \mathrm{SD}$ for a normal Japanese girl), and her $\mathrm{BMI}$ is $13.8 \mathrm{~kg} / \mathrm{m}^{2}(-1.18 \mathrm{SD}$ for a normal Japanese girl).

\section{Case 2}

Case 2 is the mother of case 1 . She delivered the first child (case 3 ) at the age of $21 \mathrm{y}$. She had complaints of headache and easy fatigue at the age of $24 \mathrm{y}$. At this time, goiter was noticed by physical examination. Thyroid function test showed elevated FT3 and FT4 and undetectable TSH in the absence of autoantibodies (FT4 $6.24 \mathrm{pg} / \mathrm{ml}$ and FT4 $2.24 \mathrm{ng} / \mathrm{ml}$ ). Ultrasonography revealed a diffuse enlargement of thyroid gland (total volume was $44.2 \mathrm{~cm}^{3}$ ) (normal range: $10.9 \pm 2.5 \mathrm{~cm}^{3}$ ), and ${ }^{123}$ I uptake was high ( $40 \%$ at $24 \mathrm{~h}$, normal range: $15-25 \%)$. Her father and younger brother were also diagnosed as having hyperthyroidism; however, detailed clinical data were not available. Based on these findings, she was diagnosed as having nonautoimmune hyperthyroidism, and administration of thiamazole was initiated. Clinical symptoms were improved; however, urticaria developed after 1 mo of treatment. Thereafter, her medication was changed to propylthiouracil $(600 \mathrm{mg} / \mathrm{d})$. Two years after diagnosis of hyperthyroidism, she was pregnant with the second child. During pregnancy, her thyroid function was stabilized with treatment of propylthiouracil at $150 \mathrm{mg} / \mathrm{d}$.

\section{Case 3}

Case 3 is the elder sister of the proband. She was born at the 40th wk of gestation following an uncomplicated delivery. Her

birth weight was $3,855 \mathrm{~g}$, her length was $52 \mathrm{~cm}$, and head circumference was $37.5 \mathrm{~cm}$. She was born 3 y before diagnosis of hyperthyroidism in her mother was done. Neonatal screening for hypothyroidism based on TSH measurement did not detect any abnormality. Because of hyperthyroidism in her younger sister, mother, and other family members (Figure 1a), her thyroid function was evaluated at the age of 5 y 9 mo. Until then, her general health was good, and her physical and neurological development were normal. Her height was $115 \mathrm{~cm}( \pm 0$ SD for a normal Japanese girl), and her BMI was $15.1 \mathrm{~kg} / \mathrm{m}^{2}$. Hormone measurement showed elevated thyroid hormone and suppressed TSH levels $(\mathrm{FT} 3=5.96 \mathrm{pg} / \mathrm{ml}, \mathrm{FT} 4=2.00 \mathrm{ng} / \mathrm{dl}$, and TSH $<0.05 \mu \mathrm{U} / \mathrm{ml}$ ) in the absence of thyroid autoantibodies. Physical examination showed no goiter, but her heart rate was slightly elevated ( 90 beats $/ \mathrm{min}$ ). Because her general condition was good, she was followed without medication. However, because her thyroid hormone and TSH levels remained high and suppressed, respectively, administration of thiamazole $(15 \mathrm{mg} / \mathrm{d})$ was started at the age of 6 y $3 \mathrm{mo}$. Because systemic urticaria developed 1 mo after the initiation of thiamazole, propylthiouracil was substituted for thiamazole. A goiter gradually became evident. At the age of $9 \mathrm{y}$, thyroid ultrasound revealed a diffuse goiter with a total volume of $8.1 \mathrm{~cm}^{3}$ (normal: $4.9 \pm 1.0 \mathrm{~cm}^{3}$ for her age) (14) and high blood flow in the thyroid tissue. She is now $10 \mathrm{y}$ old, and administration of propylthiouracil $(300 \mathrm{mg} / \mathrm{d})$ is being continued.

\section{RESULTS}

\section{Mutation Screening in TSHR}

In the proband, her younger sister, her mother, her maternal grandfather, and her maternal uncle, a heterozygous c. 1358 $\mathrm{T}>\mathrm{G}$ mutation was identified. As a result of this change, methionine at codon 453 was changed to arginine (M453R) in exon 10 of TSHR (Figure $1 \mathbf{b}, \mathbf{c}$ ). This missense mutation was present in TMD 2. The proband's father did not have this nucleotide change. At the same codon of 453, an M453T mutation was previously reported in two sporadic patients with severe nonautoimmune hyperthyroidism $(6,7)$.

\section{Cell Surface Expression of M453R}

Western blotting demonstrated that both M453R and M453T expression were similar to the wild-type (WT) receptor (Figure 2a). Further quantification of cell surface expression by flow cytometry demonstrated a reduced expression level compared with WT (Figure 2b) (WT: $100.23 \pm 10.2 \%$, M453R: $80.6 \pm 19.5 \%$, and M453T: $61.2 \pm 18.9 \%)$. The reduced cell surface expression of M453T was in agreement with the result previously reported (6).

\section{Functional Consequence on Gs-Adenylyl Cyclase and Gq/11- Phospholipase C Signaling Pathways}

Despite the lower expression level, the basal activity of both M453R (853 $\pm 110 \%)$ and M453T (923 $\pm 89 \%)$ was significantly increased compared with that of the WT (Figure 3a). The degree of constitutive activation of M453T was comparable with that of M453R. When stimulated with $100 \mathrm{mIU} / \mathrm{ml}$ of TSH, the 
a

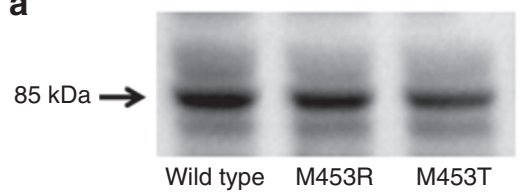

b

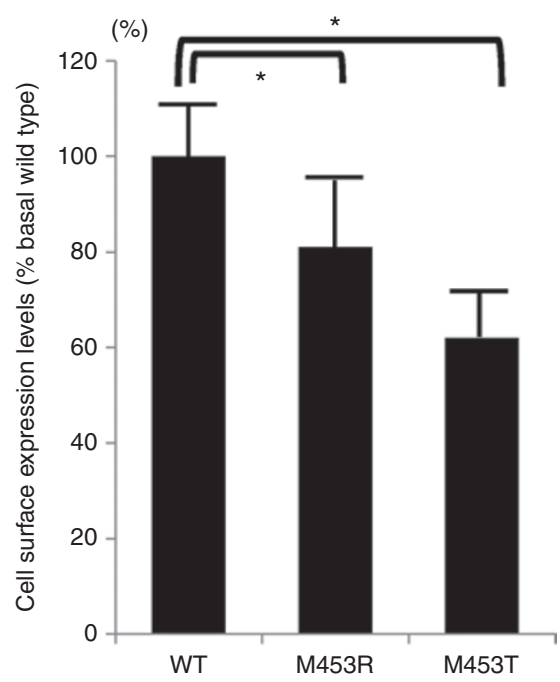

Figure 2. Cell surface expression of mutant TSHR. (a) Western blotting showed that protein expression levels of both M453R and M453T in whole cells were similar to those of wild type (WT). (b) Cell surface expression after transfection of empty pcDNA3 plasmid, WT, M453R, and M453T was measured by flow cytometry $(* P<0.05)$. Reduced expression of M453R and M453T compared with WT thyrotropin receptor (TSHR) was observed. The data represent the mean \pm SEM.

response of each mutant was significantly reduced compared with WT $(\mathrm{WT}=2,763 \pm 125 \%, \mathrm{M} 453 \mathrm{R}=1,324 \pm 637 \%$, and $\mathrm{M} 453 \mathrm{~T}=1,466 \pm 324 \%)$.

Next we studied the basal and TSH-stimulated activation of the Gq-phospholipase C signal pathway (Figure 3b). Basal activation of M453R and M453T was not significantly different from that of the WT. When each mutant was stimulated by 100 $\mathrm{mIU} / \mathrm{ml}$ of TSH, both mutants completely lost their activation capacity compared with the WT (Figure 3b).

\section{DISCUSSION}

To date, $\sim 30$ constitutively activating TSHR mutations have been reported in nonautoimmune hyperthyroidism (4-13,1519). Most of the activating mutations are present in TMD 1,2, 3 , and 5. Our mutation was also located in TMD2. Previously, two TSHR germline activating mutations have been found in TDM2 (M453T and M463V) (6,7,9,10). However, because there is no hot spot for the activating mutation, analysis of TSHR in each individual with nonautoimmune hyperthyroidism is necessary.

Two points regarding the clinical phenotypes and the genotypes of mutations of TSHR are pointed out in this study. First, regarding goiter, its onset is variable even in cases and families harboring the same mutations of TSHR $(10,11,16,18,19)$. In some patients, a goiter develops before the onset of clinical findings of hyperthyroidism (15); however, in other patients, the manifestation of hyperthyroidism precedes the onset of
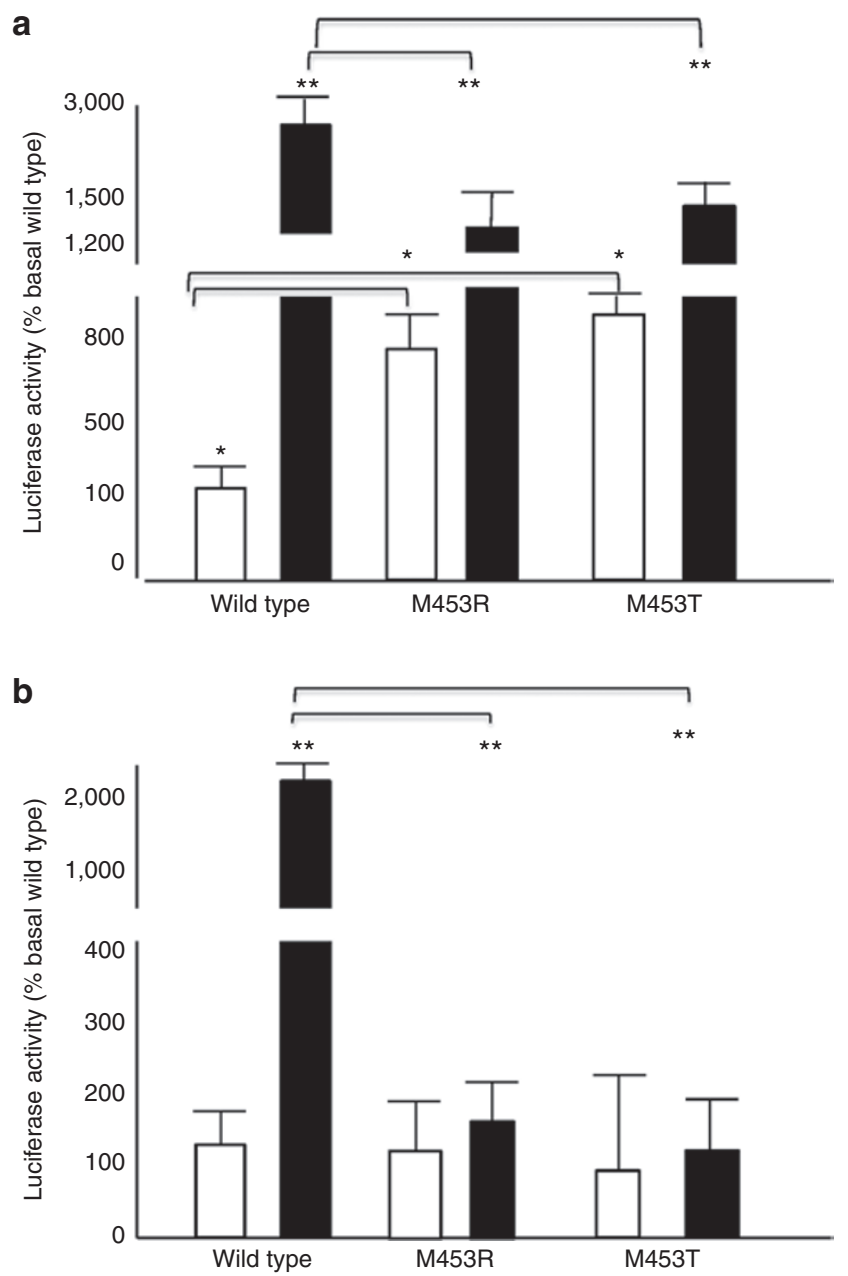

Figure 3. Functional analysis of mutant TSHR. (a) Activation of Gs-adenylyl cyclase was determined $48 \mathrm{~h}$ after transfection. Cells were stimulated with bovine thyrotropin (TSH). Basal activity is indicated by white bars; activity after stimulation with $100 \mathrm{mU}$ bovine TSH is indicated by black bars. The basal activity of the wild type (WT) was set as $100 \%$. The data represent the mean \pm SEM. The basal activity of both M453R and M453T was significantly increased compared with that of WT, indicating that these two mutants are constitutively active $\left({ }^{*} P<0.05 ;{ }^{*} P<0.01\right)$. (b) Activation of the $\mathrm{Gq} / 11$-phospholipase $\mathrm{C}$ signaling pathway was determined $48 \mathrm{~h}$ after transfection. Basal activity is indicated by white bars; and activity after stimulation with $100 \mathrm{mU}$ bovine TSH is indicated by black bars. The basal activity of the WT was set as $100 \%$. The data represent the mean \pm SEM. When M453R and M453T were stimulated by $100 \mathrm{mIU} / \mathrm{ml}$ of bovine TSH, both mutants completely lost activation capacity compared with WT $\left.{ }^{* *} P<0.01\right)$.

goiter $(7,8,11,12,16)$. In the siblings of our family, goiter was observed at 2-3 y of age after the diagnosis of hyperthyroidism. Fuhrer et al. (20) reported that follicular cell growth in the thyroid due to the constitutive activation of TSHR takes a longer period than stimulation of function. This may explain the later manifestation of goiter than that of hyperthyroidism in our siblings.

Second, hyperthyroidism in our familial cases was not severe. In the proband, poor body weight gain and tachycardia were noticed at 1 mo of age; however, hyperthyroidism was not severe. Based on the past history, her elder sister was likely to be asymptomatic, and her elevated thyroid hormone levels 
were observed by blood examination at the age of $5 \mathrm{y}$. Their mother was diagnosed at the age of $24 \mathrm{y}$. In contrast to our familial cases, previously reported patients harboring M453T mutation showed severe hyperthyroidism from the fetal period $(6,7)$. In one case, the patient exhibited goiter, tachycardia, and marked ocular symptoms at birth (6). Another patient showed hyperthyroidism from the fetal period, and thyroidectomy and radiotherapy were required to achieve a euthyroid state (7). These phenotypic differences may be due to the type of mutation in TSHR. However, an in vitro study showed that the degree of constitutive activation of the Gs-adenylyl cyclase signaling pathway of the two mutants was similar.

Winkler et al. (17) reported the clinical course and molecular mechanism in one patient with nonautoimmune hyperthyroidism caused by a C636W mutation of TSHR. The patient showed very mild symptoms and no goiter. In an in vitro study, the C636W mutant stimulated the Gs-adenylyl cyclase pathway in a constitutive manner; however, activation of Gq-phospholipase C stimulated by TSH was markedly reduced compared with the WT. Based on these findings, the authors suggested that the lack of goiter in their patient might be due to impairment of the Gq-phospholipase C signal pathway because Gq-phospholipase $\mathrm{C}$ is involved in thyroid hormone synthesis and growth of the thyroid gland as well as the Gs-adenylyl cyclase pathway(3). In this context, we compared the activation capacity of Gq-phospholipase C between M453R and M453T; however, both mutants had completely lost the capacity to activate this pathway. Therefore, our in vitro data show that the genotype alone could not explain the phenotypic severity of our familial cases with the M453T mutation. As suggested previously, other genetic and/or environmental factors are likely to influence the phenotype of nonautoimmune hyperthyroidism $(10,11,18,19)$.

In conclusion, we identified a novel mutation of TSHR causing nonautoimmune hyperthyroidism.

\section{METHODS}

\section{DNA Amplification and Sequence Analysis}

Informed consent to participate in the study was obtained from the patients and/or their parents. The ethical committee of Hokkaido University School of Medicine approved this study. Genomic DNA was extracted from peripheral leukocytes, and TSHR was amplified by PCR as described previously (21). These PCR products were purified and directly sequenced with an automated sequencer (ABI Prism; Perkin-Elmer, Wellesley, MA).

\section{Site-Directed Mutagenesis and Plasmid Construct}

Human TSHR cDNA was inserted into a human expression vector (pcDNA3.1; Invitrogen, Carlsbad, CA). M453R identified in our study was created by site-directed mutagenesis using the PrimeSTAR mutagenesis kit (Takara, Tokyo, Japan). We also created M453T, which was previously reported in patients with nonautoimmune hyperthyroidism $(6,7)$. A modified TSHR cDNA containing a FLAG epitope tag, YKDDDDK, inserted between amino acids 20 and 21 just after the signal peptide in the TSHR NH2-terminal region was constructed.

All constructs were confirmed by DNA sequencing before transfection.

\section{Expression of TSHR in Human Embryonic Kidney 293 Cells}

Human embryonic kidney (HEK) 293 cells were cultured in Dulbecco's modified Eagle's medium (Invitrogen) with $10 \%$ heatinactivated fetal bovine serum. Transient transfection was performed by using Lipofectamine 2000 (Invitrogen).
Western Blot Analysis

HEK-293 cells were plated into $75 \mathrm{~cm}^{2}$ flasks, grown to $70 \%$ confluence, and transiently transfected with $10 \mu \mathrm{g}$ WT or mutant FLAGtagged TSHR cDNA. Forty-eight hours after transfection, crude cell extracts were obtained, and samples containing $50 \mu \mathrm{g}$ of protein were separated by $10 \%$ SDS-polyacrylamide gel electrophoresis. The presence of the TSHR was detected with an anti-FLAG antibody and visualized by ECL Plus Western Blotting Detection Reagents (GE Healthcare, Little Chalfont, UK).

\section{Fluorescence-Activated Cell Sorting Analysis}

To quantify the extent of cell surface expression of TSHR, fluorescence intensity was measured using flow cytometry. HEK-293 cells grown in six-well plates were transiently transfected with $2 \mu \mathrm{g}$ WT or mutant FLAG-tagged TSHR cDNA and $0.5 \mu \mathrm{g}$ pAcGFP1-Mem (ClontechTakara, Tokyo, Japan), which results in labeling of the plasma membrane. Forty-eight hours after transfection, cells were gently scraped with Accutase-Enzyme Cell Detachment Medium (eBioscience, San Diego, CA). Detached cells were washed with ice-cold PBS, and $10^{6}$ cells were incubated for $20 \mathrm{~min}$ at $4{ }^{\circ} \mathrm{C}$ with anti-FLAG antibody diluted 1:500. Cells were washed with PBS and incubated for another $20 \mathrm{~min}$ with PE-conjugated Goat anti-mouse IgG diluted 1:250 (BioLegend, San Diego, CA) at $4{ }^{\circ} \mathrm{C}$. Cells were washed with PBS and immediately analyzed on a BD FACSCalibur flow cytometer (Becton Dickinson, Franklin Lakes, NJ). Data were analyzed using Cellquest software (Becton Dickinson). All transfections were performed in triplicate, and the experiment was repeated three times. Cell surface expression levels of TSHR were expressed relative to the levels of green fluorescent protein to control for transfection efficiency.

\section{Functional Characterization of Mutant TSHR}

Activation of $\mathrm{G}$ protein-coupled signal transduction by TSHR (WT or mutant) was studied using luciferase assays: cAMP-response element (pGL4.29; Promega, Madison, WI) and nuclear factor AT response element (pGL4.30; Promega) were used to assess the Gs/ adenylyl cyclase and Gq-phospholipase C pathway, respectively, as described in previous reports $(21,22)$.

We seeded HEK-293 cells into 12-well plates and transfected the cells with $0.5 \mu \mathrm{g}$ of each TSHR construct (WT or mutant) along with $0.5 \mu \mathrm{g}$ of each reporter vector. Forty-eight hours after transfection, the medium was changed, and the cells were incubated with Dulbecco's modified Eagle's medium with and without bovine TSH $(100 \mathrm{mU} / \mathrm{ml})$ for $30 \mathrm{~min}$ (Sigma, St. Louis, MO). The assay was performed according to the manufacturer's protocol. Luciferase activity was normalized to $\beta$-galactosidase. All transfections were performed in triplicate, and the experiment was repeated three times. Values were represented as the mean \pm SEM. Statistical analysis was carried out using the MannWhitney $U$ test.

\section{ACKNOWLEDGMENTS}

We thank Satoshi Narumi and Tomonobu Hasegawa from the Department of Pediatrics, Keio University School of Medicine, for their gift of TSHR expression vector.

\section{STATEMENT OF FINANCIAL SUPPORT}

No financial assistance was received to support this study.

Disclosure: The authors have no conflicts of interest to declare.

\section{REFERENCES}

1. Vassart G, Dumont JE. The thyrotropin receptor and the regulation of thyrocyte function and growth. Endocr Rev 1992;13:596-611.

2. Kleinau G, Krause G. Thyrotropin and homologous glycoprotein hormone receptors: structural and functional aspects of extracellular signaling mechanisms. Endocr Rev 2009;30:133-51.

3. Kero J, Ahmed K, Wettschureck N, et al. Thyrocyte-specific Gq/G11 deficiency impairs thyroid function and prevents goiter development. J Clin Invest 2007;117:2399-407.

4. Duprez L, Parma J, Van Sande J, et al. Germline mutations in the thyrotropin receptor gene cause non-autoimmune autosomal dominant hyperthyroidism. Nat Genet 1994;7:396-401. 
5. Kopp P, van Sande J, Parma J, et al. Brief report: congenital hyperthyroidism caused by a mutation in the thyrotropin-receptor gene. N Engl J Med 1995;332:150-4.

6. de Roux N, Polak M, Couet J, et al. A neomutation of the thyroid-stimulating hormone receptor in a severe neonatal hyperthyroidism. J Clin Endocrinol Metab 1996;81:2023-6.

7. Lavard L, Sehested A, Brock Jacobsen B, et al. Long-term follow-Up of an infant with thyrotoxicosis due to germline mutation of the TSH receptor gene (Met453Thr). Horm Res 1999;51:43-6.

8. Biebermann H, Schöneberg T, Hess C, Germak J, Gudermann T, Grüters A. The first activating TSH receptor mutation in transmembrane domain 1 identified in a family with nonautoimmune hyperthyroidism. J Clin Endocrinol Metab 2001;86:4429-33.

9. Fuhrer D, Warner J, Sequeira M, Paschke R, Gregory J, Ludgate M. Novel TSHR germline mutation (Met463Val) masquerading as Graves' disease in a large Welsh kindred with hyperthyroidism. Thyroid 2000;10:1035-41.

10. Ferrara AM, Capalbo D, Rossi G, et al. A new case of familial nonautoimmune hyperthyroidism caused by the M463V mutation in the TSH receptor with anticipation of the disease across generations: a possible role of iodine supplementation. Thyroid 2007;17:677-80.

11. Akcurin S, Turkkahraman D, Tysoe C, et al. A family with a novel TSH receptor activating germline mutation (p.Ala485Val). Eur J Pediatr 2008;167:1231-7.

12. Agretti P, De Marco G, Biagioni M, et al. Sporadic congenital nonautoimmune hyperthyroidism caused by $\mathrm{P} 639 \mathrm{~S}$ mutation in thyrotropin receptor gene. Eur J Pediatr 2012;171:1133-7.

13. Biebermann H, Winkler F, Handke D, et al. New pathogenic thyrotropin receptor mutations decipher differentiated activity switching at a conserved helix 6 motif of family A GPCR. J Clin Endocrinol Metab 2012;97:E228-32.
14. Ueda D. Normal volume of the thyroid gland in children. J Clin Ultrasound 1990;18:455-62.

15. Arturi F, Chiefari E, Tumino S, et al. Similarities and differences in the phenotype of members of an Italian family with hereditary non-autoimmune hyperthyroidism associated with an activating TSH receptor germline mutation. J Endocrinol Invest 2002;25:696-701.

16. Nwosu BU, Gourgiotis L, Gershengorn MC, Neumann S. A novel activating mutation in transmembrane helix 6 of the thyrotropin receptor as cause of hereditary nonautoimmune hyperthyroidism. Thyroid 2006;16:505-12.

17. Winkler F, Kleinau G, Tarnow P, et al. A new phenotype of nongoitrous and nonautoimmune hyperthyroidism caused by a heterozygous thyrotropin receptor mutation in transmembrane helix 6. J Clin Endocrinol Metab 2010;95:3605-10.

18. Gozu HI, Lublinghoff J, Bircan R, Paschke R. Genetics and phenomics of inherited and sporadic non-autoimmune hyperthyroidism. Mol Cell Endocrinol 2010;322:125-34.

19. Lueblinghoff J, Mueller S, Sontheimer J, Paschke R. Lack of consistent association of thyrotropin receptor mutations in vitro activity with the clinical course of patients with sporadic non-autoimmune hyperthyroidism. J Endocrinol Invest 2010;33:228-33.

20. Fuhrer D, Lewis MD, Alkhafaji F, et al. Biological activity of activating thyroid-stimulating hormone receptor mutants depends on the cellular context. Endocrinology 2003;144:4018-30.

21. Narumi S, Nagasaki K, Ishii T, et al. Nonclassic TSH resistance: TSHR mutation carriers with discrepantly high thyroidal iodine uptake. J Clin Endocrinol Metab 2011;96:E1340-5.

22. Cheng Z, Garvin D, Paguio A, Stecha P, Wood K, Fan F. Luciferase reporter assay system for deciphering GPCR pathways. Curr Chem Genomics 2010;4:84-91. 